\title{
Verzeichnis und Inhaltsübersicht der Urteilsanmerkungen
}

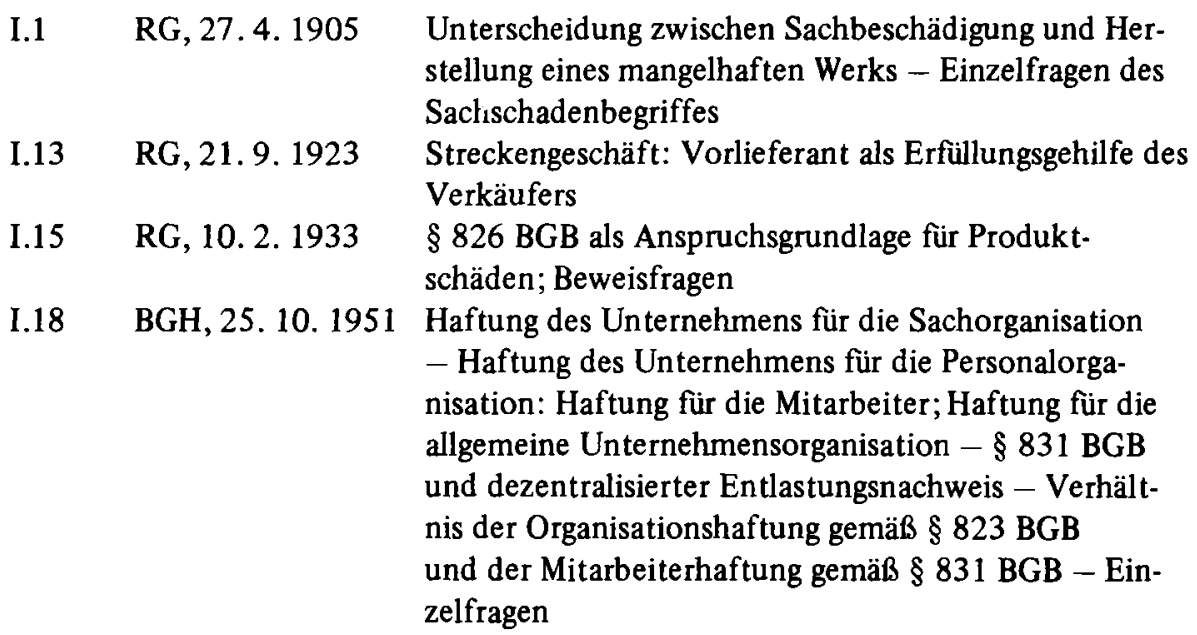

1.27 BGH, 29. 10. 1956 Allgemeine Geschäftsbedingungen: Inhaltsgrenzen Begriff der AGB bzw. der formularmäßigen Klauseln - Inhaltsgrenzen - Haftungsfreizeichnungsklauseln - Ausschluß der Schadensersatzhaftung - Abänderung der kaufrechtlichen Gewährleistungsrechte - Abänderung der werkvertragsrechtlichen Gewährleistungsrechte - Zahlungspflichten des Kunden und Gewährleistungsverpflichtung des Lieferanten

I.48 BGH, 30. 4. 1963 Rechtliche Relevanz von Werbeangaben - vertragsrechtliche Relevanz - deliktsrech tliche Relevanz

I.56 BGH, 29. 5. 1968 Formularmäßige Abbedingung der Schadensersatzhaftung für das Fehlen zugesicherter Eigenschaften: Unterschied zwischen Eigenschaf tszusicherungen mit bloßer Vergewisserungsfunktion und Eigenschaftszusicherungen mit der Funktion einer Absicherung gegen Mangelfolgeschäden; Bedeutung bei Konstruktionsfehlern sowie bei Fabrikationsfehlern - Werkvertragsrecht - Verschuldensunabhängigkeit der Schadensersatzhaftung gemäß § 463 BGB

I.62 BGH, 28.9.1970 Anscheinsbeweis und Beweislastumkehr - retrospektiver Anscheinsbeweis - Beweisvereitelung bzw. 
I.72 BGH, 5.7.1972

III.1 LG Hanau, 28.2. 1955

III.2 LG Lindau, 26. 4. 1955

III.3 LG Freiburg, 17.2. 1959

III.6 LG Kleve, 26. 2. 1964

III.12 LG Heidelberg, 25.7. 1973

III.13 LG Saarbrücken, 2.7. 1974

I.85 BGH, 19.2. 1975

I.86 BGH, 3.6. 1975
Verpflichtung des Herstellers zur Aufbewahrung der Schadensteile

Vorliegen von Eigenschaftszusicherungen, insbesondere Eignung für einen bestimmten Verwendungszweck, Leistungsangaben, DIN-Normen - Vorausse tzungen für eine Erstreckung der Eigenschaftszusicherung auf Mangelfolgeschäden - Umfang der mit der Erstrekkung auf Mangelfolgeschäden verbundenen Absicherungsfunktion

Mitarbeiter- und Organisationshaftung ( $\S \S 831,823$ BGB)

Ineinandergreifen von Fabrikations- und Qualitätskontrollhaftung - Hundertprozent-Kontrollen - Stichproben-Kontrollen

Quasi-Herstellerhaftung bei Vertrieb eines Fremdproduktes unter eigenem Warenzeichen, eigener Handelsmarke oder als eigenes Produkt - Inhalt der QuasiHerstellerhaftung

Assembler-Haftung bei Fabrikationsfehlern - Einzelfragen der Drittunternehmerauswahl- bzw. Kontrollhaftung

Beschränkung einer Eigenschaftszusicherung auf einen Vergewisserungseffekt

Deliktsrechtliche Importeurhaftung - Kollisionsrecht

Nichtberücksich tigung der bei Produkterprobung gewonnenen Erkenntnisse - vertragsrechtliche Instruktionshaftung - funktioneller Zusammenhang zwischen Konstruktionshaftung und Instruktionshaftung - Anwendungsbereiche der Instruktionshaftung - Fallbereiche der Instruktionshaftung - Instruktionshaftung und statistische Häufigkeit bzw. Seltenheit des Schadenseintritts - Beweislastumkehr im Bereich des Kausalitätsnachweises

Alternativer Fehlernachweis - Erfordernis der Verantwortung des Beklagten für beide potentiellen Fehler - Verantwortung des Fabrikationsleiters für Instruktionsfehler - Beweislastumkehr im Bereich der Mitarbeiter-Eigenhaftung: rechtspolitischer Stellen- 
wert der Entscheidung - Anwendungsvoraussetzungen für die Beweislastumkehr im Bereich der MitarbeiterEigenhaftung - sozialpsychologische Bedeutung der Entscheidung - unmittelbare deliktsrechtliche Haftung des Mitarbeiters gegenüber dem Endgeschädigten für in seinem Verantwortungsbereich gesetzte Fehlerursachen - Assembler-Haftung - Quasi-Herstellerhaftung 